\title{
Isolated Splenic Tuberculosis in an Immunocompetent Patient: A Rare Case
}

\author{
Mohamed Chablou $^{1}$, Rachid Jabi ${ }^{1}$, Ahmed Id M'barek ${ }^{2}$, Noura Seghrouchni ${ }^{3}$, Mohammed Bouziane ${ }^{1}$ \\ 1. General Surgery, Mohammed VI University Hospital/Faculty of Medicine and Pharmacy of Oujda, Mohammed First \\ University of Oujda, Oujda, MAR 2. Pulmonary Medicine, Mohammed VI University Hospital/Faculty of Medicine and \\ Pharmacy of Oujda, Mohammed First University of Oujda, Oujda, MAR 3. Pathology, Mohammed VI University \\ Hospital/Faculty of Medicine and Pharmacy of Oujda, Mohammed First University of Oujda, Oujda, MAR
}

Corresponding author: Mohamed Chablou, m.chablou@gmail.com

\section{Abstract}

Tuberculosis (TB) is one of the top 10 causes of death worldwide and the leading cause of death from a single infectious agent. Despite early diagnosis and improvements in medical science, the incidence of the disease is still a major public health problem in developing countries. Splenic tuberculosis is quite rare and occurs mostly as a part of miliary tuberculosis in individuals with immunosuppression. Isolated splenic tuberculosis is extremely rare in immunocompetent patients. We report a case of an immunocompetent man with isolated splenic tuberculosis.

Categories: General Surgery, Infectious Disease

Keywords: splenic tuberculosis, tuberculosis, miliary, disseminated tuberculosis

\section{Introduction}

Tuberculosis is defined as a microbial, contagious disease caused by infection with Mycobacterium tuberculosis. It remains a real public health problem in developing countries [1]. Extrapulmonary tuberculosis accounts for almost $16 \%$ of all cases [2]. Isolated splenic tuberculosis is extremely rare, particularly in immunocompetent persons. It is normally seen as part of miliary tuberculosis. The incidence of splenic tuberculosis may be variable depending on the prevalence of the disease in a particular geographical area [3]. The present series reported $4 \%-12 \%$ of splenic tuberculosis in patients subjected to a diagnostic splenectomy [3]. In this case report, we report a rare case of 62-year-old men with solitary splenic tuberculosis.

\section{Case Presentation}

A 62-year-old man presented to our outpatient service with left hypochondriac pain radiating to the shoulder associated with low-grade fever, anorexia, and weight loss for five weeks' duration. There was no history of cough, breathlessness, chest pain, or hemoptysis. His medical history did not include any

Review began 02/12/2021 Review ended 02/15/2021 Published 02/21/2021

\section{๑) Copyright 2021}

Chablou et al. This is an open access article distributed under the terms of the Creative Commons Attribution License CC-BY 4.0., which permits unrestricted use, distribution, and reproduction in any medium, provided the original author and source are credited. tuberculosis.

On clinical examination, his body temperature was $38.3^{\circ} \mathrm{C}$. Abdominal palpation revealed mildly enlarged and tender spleen without any other significant findings.

His hemogram revealed normocytic normochromic anemia (hemoglobin: $9 \mathrm{~g} / \mathrm{dl}$ ); leukocyte and platelet counts were normal. Liver and renal function tests were within normal limits. C-reactive protein (CRP) was elevated (130 mg/l). Hepatitis B, hepatitis C, and human immunodeficiency virus (HIV) markers were negative. Chest X-ray was unremarkable.

Abdominal ultrasound showed splenomegaly with the presence of multiple hypo-echoic lesions. Abdominal computed tomography (CT) scan showed a heterogeneous enlarged spleen measuring $168 \mathrm{~mm}$ in size, with multiple hypodense areas, some of which contain centrally irregular necrosis, the largest at the mid-splenic level, measuring $65 \times 57 \mathrm{~mm}$, associated with infiltration of perisplenic fat (Figure 1). 


\section{Cureus}

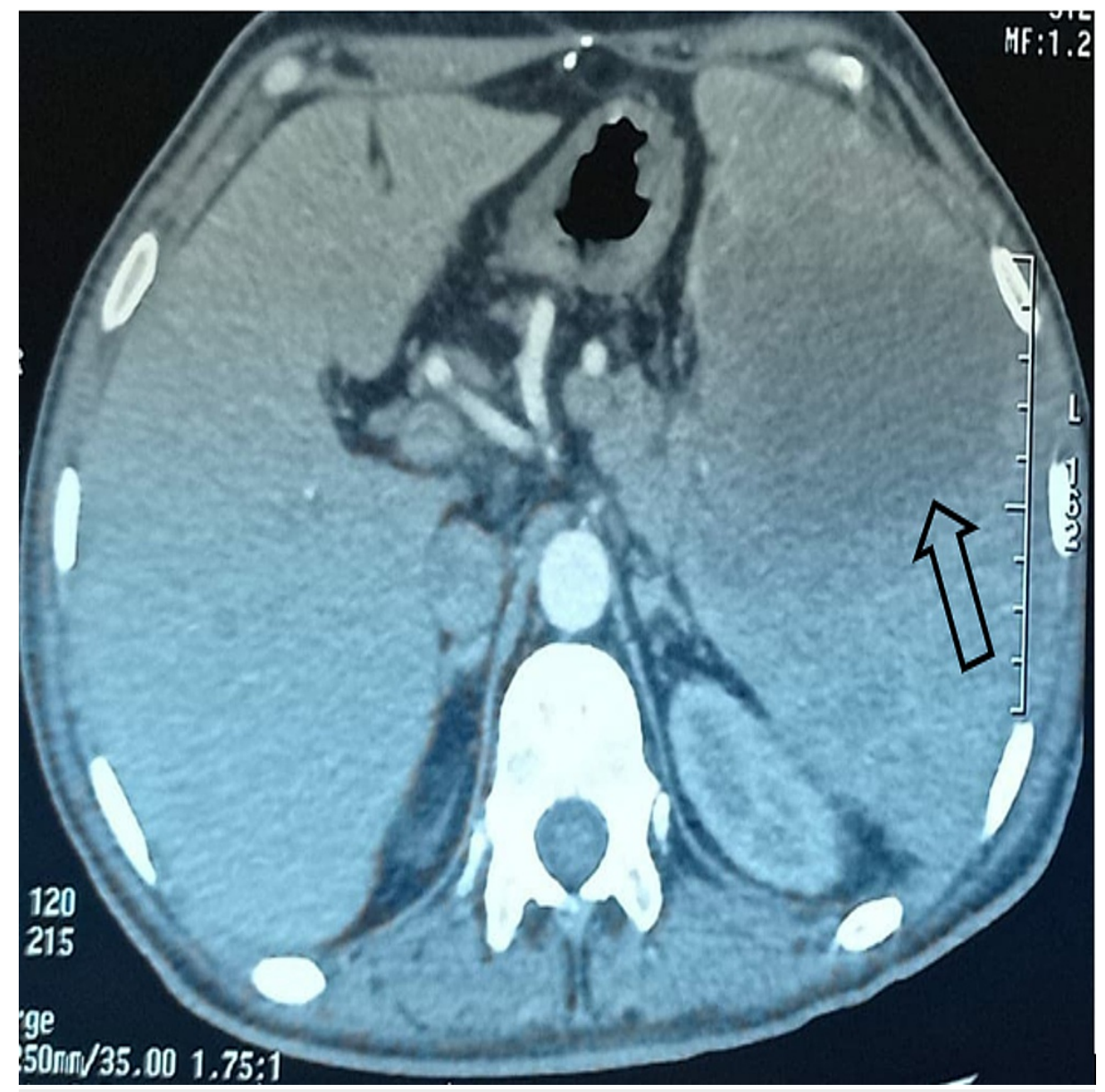

FIGURE 1: Computed tomography scan showing hypodense areas within the spleen (black arrow)

Fine-needle aspiration was not performed, as it was technically unfeasible. Then, the patient underwent open splenectomy for diagnostic and therapeutic purposes (Figure 2).

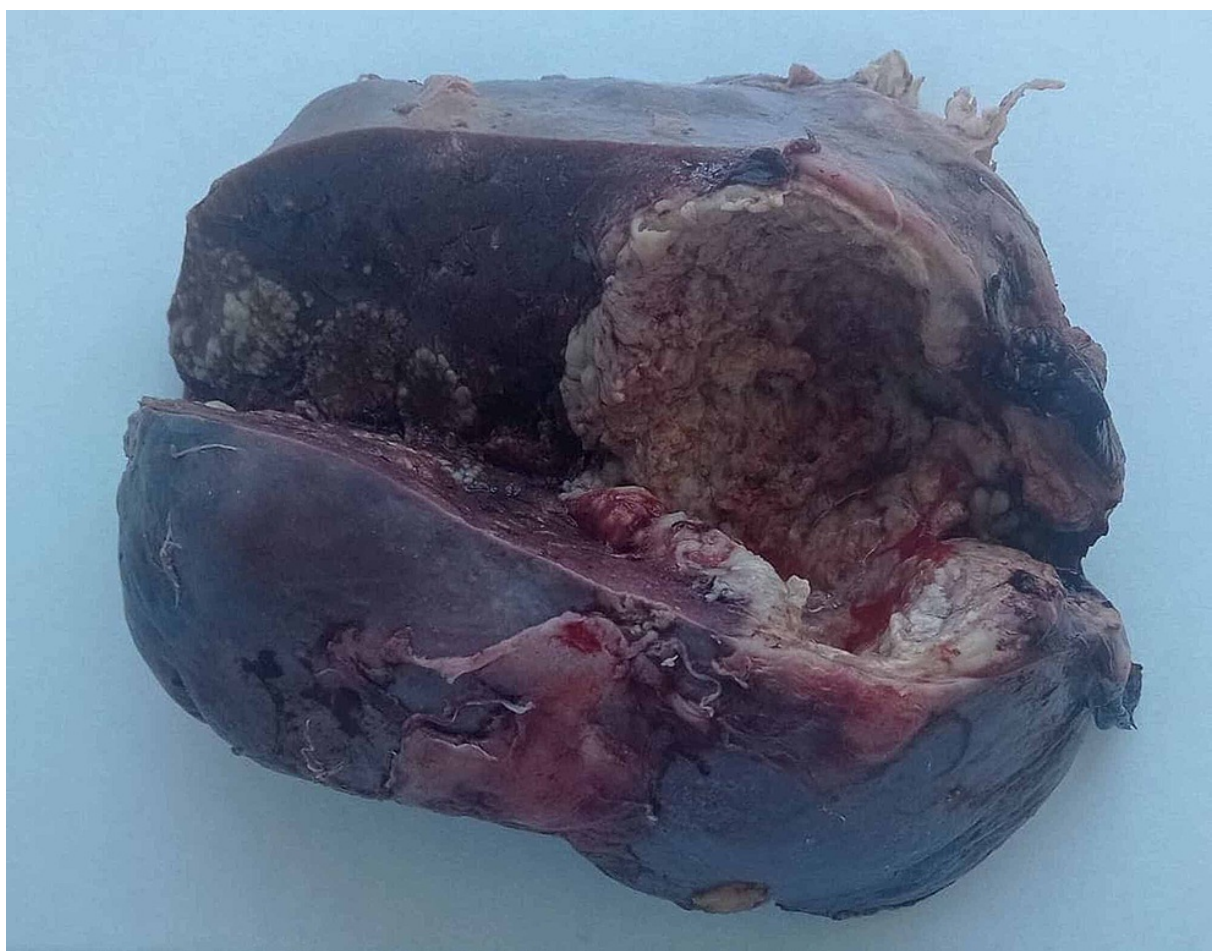


A histologic report showed splenic parenchyma reshaped by a granulomatous inflammatory infiltrate with large confluent epithelioid granulomas, associated with the presence of giant cells with foci of caseation necrosis. Ziehl-neelsen stain did reveal Mycobacterium tuberculosis and was compatible with splenic tuberculosis.

Therefore, a final diagnosis of splenic tuberculosis was made, and the patient was started on quadruple antituberculosis therapy four drugs for two months: isoniazid $(5 \mathrm{mg} / \mathrm{kg})$, rifampicin $(10 \mathrm{mg} / \mathrm{kg})$, pyrazinamide $(25 \mathrm{mg} / \mathrm{kg})$, and ethambutol $(20 \mathrm{mg} / \mathrm{kg})$, and then two drugs for the next four months: isoniazid and rifampicin. The patient remained asymptomatic after a six-month follow-up with an improvement of his general condition.

\section{Discussion}

Abdominal tuberculosis is an infection caused by Mycobacterium tuberculosis that affects the gastrointestinal and urinary tract, as well as the peritoneum, lymph nodes, or solid organs (liver, spleen, and pancreas) [4]. The World Health Organization estimates that extrapulmonary tuberculosis accounts for about $16 \%$ of all tuberculosis cases in 2019 [2].

Isolated splenic tuberculosis is very rare in immunocompetent subjects, and more frequent in immunocompromised patients, principally in HIV-infected patients [5].

Spleen is the third most common organ (lung $100 \%$, liver $82 \%$, spleen $75 \%$, lymph nodes $55 \%$, and bone marrow $41 \%$ ) involved in miliary tuberculosis [6-7].

Our patient was immunocompetent. He had neither a history of TB nor showed evidence of TB in any other organ and no immunosuppressive condition. The diagnosis of splenic tuberculosis is difficult because of non-specific clinical manifestations. In our case, the chief complaints and symptoms were abdominal pain associated with low-grade fever and weight loss. In other case reports of splenic tuberculosis, the principal symptom was abdominal discomfort, without fever or weight loss [8-9].

Laboratory data, which are often disturbed, do not provide certain elements in favor of the diagnosis. On the hemogram, signs of hypersplenism are present in 35\% [10], associated anemia, leukopenia, even thrombocytopenia, which is not the case of our patient, apart from normocytic normochromic anemia at 9 $\mathrm{g} / \mathrm{dl}$, these disturbances of the hemogram can be observed in other hemopoietic pathologies such as lymphoma and leukemia. Thus, high CRP can be seen in pyogenic abscesses and hydatid cysts.

Ultrasound allows confirmation of clinically uncertain splenomegaly, detection, and characterization of focal lesions, objectification of other associated pathologies, and guidance of fine-needle aspiration [11]. Three ultrasound imaging aspects have been described: the micronodular or miliary form is rarely diagnosed at an early stage [12], the macronodular form that corresponds either to tubers in focus or cold abscesses, and the pseudotumoral form. In our patient, abdominal ultrasound showed splenomegaly with the presence of multiple hypo-echoic lesions.

The abdominal CT scan allows a precise topographical assessment of the splenic lesions and associated regional damage; in our case, the splenic damage was isolated. Thus, the sensitivity of the scanner in splenic abscesses is around $90 \%$ to $100 \%$ [13]. However, splenic abscesses of tubercular origin can pose a diagnostic problem with pyogenic abscesses, primary tumors, and hydatid cysts [14-15].

The non-specificity of the clinical, biological, and radiological signs makes histological examination essential for the diagnosis of an isolated splenic lesion especially by fine-needle aspirate, splenic biopsy, or splenectomy. The fine needle aspiration cytology is a valuable tool, with a sensitivity of $88 \%$ and specificity of up to $100 \%$ [16]. In our case, fine-needle aspiration was not performed, as it was technically unfeasible.

A final diagnosis of splenic tuberculosis was made upon histopathological findings, and quadruple antitubercular therapy (isoniazid, rifampicin, pyrazinamide, and ethambutol) was started for two months followed by four months of isoniazid and rifampicin with an improvement in the general condition of the patient [17].

\section{Conclusions}

Isolated splenic tuberculosis remains rare, even in countries where tuberculosis is endemic such as Morocco. It poses a problem of differential diagnosis, linked to clinical polymorphism and the lack of biological and 
radiological specificity. Directed biopsy in these cases is of great diagnostic and sometimes therapeutic interest, making it possible to avoid unnecessary splenectomies. When the diagnosis of splenic tuberculosis is made preoperatively, splenectomy could be considered for therapeutic purposes to eradicate a septic source resistant to medical treatment or in the case of complications such as splenic rupture. It could be considered for diagnostic purposes when percutaneous procedures are contraindicated (hemostasis disorder), inconclusive, or technically unfeasible as seen in our case.

\section{Additional Information \\ Disclosures}

Human subjects: Consent was obtained or waived by all participants in this study. Conflicts of interest: In compliance with the ICMJE uniform disclosure form, all authors declare the following: Payment/services info: All authors have declared that no financial support was received from any organization for the submitted work. Financial relationships: All authors have declared that they have no financial relationships at present or within the previous three years with any organizations that might have an interest in the submitted work. Other relationships: All authors have declared that there are no other relationships or activities that could appear to have influenced the submitted work.

\section{References}

1. Pramesh CS, Tamhankar AP, Rege SA, Shah SR: Splenic tuberculosis and HIV-1 infection. Lancet. 2002, 359:353. 10.1016/s0140-6736(02)07511-6

2. World Health Organization. Global tuberculosis report. (2018). https://apps.who.int/iris/bitstream/handle/10665/336069/9789240013131-eng.pdf.

3. Pottakkat B, Kumar A, Rastogi A, Krishnani N, Kapoor VK, Saxena R: Tuberculosis of the spleen as a cause of fever of unknown origin and splenomegaly. Gut Liver. 2010, 4:94-97. 10.5009/gnl.2010.4.1.94

4. Shreshtha S, Ghuliani D: Abdominal tuberculosis: a retrospective analysis of 45 cases . Indian J Tuberc. 2016, 63:219-224. 10.1016/j.ijtb.2016.09.008

5. Cobelschi C, Maier A, Hogea MD, Gheorghiu AR, Toader I: Splenic tuberculosis - case report . Chirurgia. 2016, 111:165-169.

6. Raviraj S, Gogia A, Kakar A, Byotra SP: Isolated splenic tuberculosis without any radiological focal lesion . Case Rep Med. 2015, 2015:130209. 10.1155/2015/130209

7. Nayyar V, Ramakrishna B, Mathew G, Williams RR, Khanduri P: Response to antituberculosis chemotherapy after splenectomy. J Intern Med. 1993, 233:81-83. 10.1111/j.1365-2796.1993.tb00653.x

8. Lin SF, Zheng L, Zhou L: Solitary splenic tuberculosis: a case report and review of the literature . World J Surg Oncol. 2016, 14:154. 10.1186/s12957-016-0905-6

9. Fooladi AAI, Hosseini MJ, Azizi T: Splenic tuberculosis: a case report. Int J Infect Dis. 2009, 13:273-275. 10.1016/j.ijid.2008.11.002

10. Gupta A: Splenic tuberculosis: a comprehensive review of literature. Pol Przegl Chir. 2018, 6:49-51. 10.5604/01.3001.0012.1754

11. Venkataramu NK, Gupta S, Sood BP, Gulati M, Rajawanshi A, Gupta SK, Suri S: Ultrasound guided fine needle aspiration biopsy of splenic lesions. Br J Radiol. 1999, 72:953-956. 10.1259/bjr.72.862.10673946

12. Boverie JH, Dondelinger RF: Imagerie de la rate [Article in French]. Encycl Méd Chir. 1995, 33605:13.

13. Wang Y, He G, Zhan W, Jiang H, D Wu D, Wang D, Tang A: CT findings in splenic tuberculosis . J Belge Radiol. 1998, 81:90-91.

14. Mahi M, Chaouir S, Amil T, Hanine A, Benameur M: Tuberculose splénique isolée. Un nouveau cas [Article in French]. J Radiol. 2002, 83:479-481.

15. Afifi R, Benazouz M, Sassenou I, Essaid A, Sebti MF: Drainage percutané des abcès de la rate: à propos de quatre observations [Article in French]. Ann Gastroenterol Hépatol. 1998, 34:243-250.

16. Pottakkat B, Kumar A, Rastogi A, Krishnani N, Kapoor VK, Saxena R: Tuberculosis of the spleen as a cause of fever of unknown origin and splenomegaly. Gut Liver. 2010, 4:94-97. 10.5009/gnl.2010.4.1.94

17. Huang CT, Leu HS, Lee MH: Tuberculous splenic abscess; a case report and literature review . Changgeng Yi Xue Za Zhi. 1995, 18:77-81. 